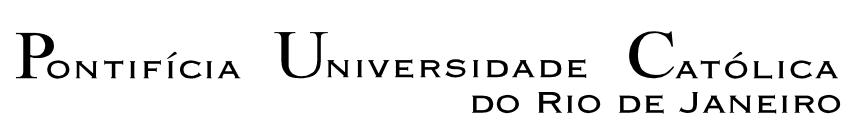

Renato Caixeta da Silva

Representações do livro didático de inglês: análise dos discursos de produtores e usuários com base na Linguística Sistêmico-Funcional

Tese de Doutorado

Tese apresentada como requisito parcial para obtenção do título de Doutor pelo Programa de PósGraduação em Letras da PUC-Rio.

Orientadora: Prof ${ }^{\mathrm{a}}$. Barbara Jane Wilcox Hemais

Rio de Janeiro

Março de 2012 


$$
\text { Pontifícia Universidade } \text { CAtólica }_{\text {do Rio de Janeiro }}
$$

Renato Caixeta da Silva

\section{Representações do livro didático de inglês: análise dos discursos de produtores e usuários com base na Linguística Sistêmico-Funcional}

Tese apresentada como requisito parcial para obtenção do título de Doutor pelo Programa de Pós-Graduação em Letras da PUC-Rio. Aprovada pela Comissão Examinadora abaixo assinada:

Profa. Barbara Jane Wilcox Hemais

Orientadora

Profa. Lúcia Pacheco de Oliveira

Profa. Inés Kayon de Miller

Departamento de Letras - PUC-Rio

Profa. Maria Elisa Knust Silveira

UFF

Profa. Gisele de Carvalho

UERJ

Profa. Denise Berruezo Portinari Coordenadora Setorial do Centro de Teologia

e Ciências Humanas - PUC-Rio

Rio de Janeiro, 15 de março de 2012 
Todos os direitos reservados. É proibida a reprodução total ou parcial do trabalho sem autorização da universidade, do autor e do orientador.

\section{Renato Caixeta da Silva}

Graduou-se em Letras pela UFMG em 1992, habilitação em Português e Inglês. Tornou-se Mestre em Letras, Linha Linguística Aplicada ao Ensino de Línguas Estrangeiras pela mesma universidade em 1998. Tem experiência como professor de inglês em instituições públicas e privadas de ensino fundamental, médio, superior e cursos de idiomas. Desde 1997 é professor efetivo do CEFET-MG, tendo sido coordenador da área de Língua Estrangeira por três mandatos. Foi presidente da APLIEMGE entre 1999 e 2001, membro de comissões organizadoras de eventos da área, e tem artigos e capítulos de livros publicados sobre ensino e aprendizagem de línguas.

Silva, Renato Caixeta da
Representações do livro didático de inglês: análise
dos discursos de produtores e usuários com base na
linguística sistêmico-funcional / Renato Caixeta da Silva;
orientadora: Barbara Jane Wilcox Hemais - 2012.
$\quad 332$ f. : il. (color.) ; $30 \mathrm{~cm}$
Tese (doutorado)-Pontifícia Universidade Católica
do Rio de Janeiro, Departamento de Letras, 2012 .
Inclui bibliografia
1. Letras - Teses. 2. Livro didático de inglês. 3.
Discurso. 4. Representações. 5. Linguística aplicada. 6.
Linguística sistêmico-funcional. 7. Produtores. 8. Usuários.
I. Hemais, Barbara Jane Wilcox. II. Pontifícia Universidade
Católica do Rio de Janeiro. Departamento de Letras. III.
Título.


A todos nós, professores de inglês, usuários ou não do livro didático, para entendermos melhor este objeto, e não termos que dizer que "a lição sabemos de cor, só nos resta aprender!" (Beto Guedes) 


\section{Agradecimentos}

Há muito que dizer neste momento, e valho-me da ajuda de autores mineiros! Assim, agradeço:

A Deus, por me permitir chegar até aqui, e porque "o fruto do trabalho é mais que sagrado" (Beto Guedes).

À professora Barbara Hemais, orientadora, por ter me aceitado, acreditado e apostado em mim sem muito me conhecer, pelos momentos de dedicação, preocupação e paciência. "Nunca me esquecerei desse(s) acontecimento(s) na vida de minhas retinas tão fatigadas" (Carlos Drummond de Andrade).

Ao CEFET-MG, nas figuras de seus diretores e dos meus colegas professores de línguas estrangeiras, que permitiram minha ausência para a realização desta tese em outras terras. "Toda essa gente que convive com a gente, (...) passa a ser gente dentro da gente" (Fernando Sabino).

À CAPES e à PUC-Rio pelos auxílios financeiros concedidos, importantes para a realização dos estudos. Com estes auxílios, foi possível ter "a certeza de que era preciso continuar" (Fernando Sabino).

Aos representantes das editoras Richmond, Cambridge, Oxford University Press, Longman Pearson, Macmillan, pelas solicitações atendidas e informações fornecidas. Agradeço “com (...) a alma repleta de chão” (Milton Nascimento).

Às professoras Barbara Hemais, Inês K. de Miller, Lúcia P. de Oliveira, Maria do Carmo L. de Oliveira pelas oportunidades de aprendizado neste doutorado, e as conversas sobre este trabalho. Às professora Maria Elisa Knust e Lúcia Pacheco, pelas observações e sugestões preciosas no Exame de Qualificação. A convivência com essas professoras me faz pensar que "obrei quanto o discurso me guiava,/ouvi aos sábios quando errar temia;/aos bons no gabinete o peito abria" (Tomaz Antônio Gonzaga).

À Chiquinha, secretária eficiente e cordial, que, com carinho e paciência, me recebia presencialmente e online para sanar dúvidas, explicar procedimentos, fazer matrículas; uma pessoa "que é só passar pela gente que a gente fica contente, (...) que sente o que a gente sente e passa isto docemente (...) que vive como a gente vive, (...) que fala e nos olha na face" (Fernando Sabino). 
Aos colegas doutorandos e mestrandos da PUC-Rio, pelo convívio, as conversas, as trocas de conhecimento. "Acho que tudo que acontece é feito pra gente aprender cada vez mais, é pra ensinar a gente a viver" (Adélia Prado).

À Mari e D. Fausta, em especial, que me receberam, e de landladies, tornaram-se excelentes amigas, fazendo de sua casa o porto seguro de um mineiro. Por causa dessas pessoas, "outras são as fortunas, que me agouro,/ ganhei saudades, adquiri afetos,/ vou fazer destes bens melhor tesouro" (Tomaz Antonio Gonzaga).

Aos professores que participaram desta pesquisa, pessoas que sabem que "é preciso ter sonho sempre,/Quem traz na pele essa marca / Possui a estranha mania de ter fé na vida" (Milton Nascimento \& Fernando Brant).

Aos alunos que se dispuseram a participar deste estudo, essa "folha da juventude" cheia de "alegria e muito sonho/ espalhados no caminho" (Milton Nascimento).

Às pessoas que, nesses anos, se preocuparam com minhas viagens, meus afazeres, e procuraram ajudar: minha mãe Madalena, preocupada com possíveis acontecimentos indesejáveis noutra cidade; meu sogro, Nonô, estando junto aos meus na minha ausência; Rose, prestativa, presente, e cuidando de nosso lar. "O que a memória ama, fica eterno" (Adélia Prado).

Ao colega professor doutor, e compadre Vicente A. Parreiras, pelas leituras, conversas, comentários, sugestões, revisões. Este é um amigo "pra se guardar debaixo de sete chaves dentro do coração" (Milton Nascimento); e também à Mariazinha, "gente boa que pôs o pé na profissão" como nós, pelas leituras de revisão, mostrando-me o que eu já não via mais.

À Vera Dias, pela paciência e a presteza em ajudar-me num auto-entendimento, e me fazendo perceber "que a vida me fez assim,(...) eu caçador de mim" (Milton Nascimento \& Fernando Brant).

À Emília, professoraesposaamiga, pelos anos de convivência, pelo incentivo, a aceitação de minha ausência, a compreensão da importância destes momentos. Para você, só me resta dizer que "não sei sair cantando sem cantar você,/Eu sei cantar mas conto com você,/Que eu vou seguir mas vou seguir você./Queria que assim sabendo que a gente se quer/Queria me rimar no teu colo, mulher/Vencer a vida donde ela vier / Ganhar o seu chegar no chegar meu / Dar de mim o homem que é seu" (Celso Adolfo).

Ao Mateus e à Monique, filhos amados, simplesmente por serem quem são. Sua chegada no início do doutorado fez tudo o mais ser suportado, acreditado, aceito, entendido, aprendido, amado e até desestabilizado. Vocês ainda vão entender que "aquele jeito que você (s) me olhou(ram)/ Varreu meu pensamento/ Todas as coisas saíram do chão / E eu me esqueci de tudo / E antes que eu me desse conta / Já era seu meu querer./ Foi como o sol que desponta/ Uma montanha dourada/ Na terra do faz de conta/ Pra me banhar de prazer" (Vander Lee). 


\section{Resumo}

Silva, Renato Caixeta da; Hemais, Barbara Jane Wilcox. Representações do livro didático de inglês: análise dos discursos de produtores e usuários com base na Linguística Sistêmico-Funcional. Rio de Janeiro, 2012. 332 p. Tese de Doutorado - Departamento de Letras, Pontifícia Universidade Católica do Rio de Janeiro.

Esta tese tem como tópico de pesquisa as representações acerca de livros didáticos de inglês construídas na sociedade por seus produtores (autores e editores) e por seus usuários (professores e alunos). A Linguística SistêmicoFuncional e conhecimentos sobre representações produzidos nas áreas de Estudos Culturais e Psicologia Social constituem os fundamentos teóricos deste estudo, pautando-se por uma visão de construção social da realidade. Mais especificamente, servem como guia de análise uma proposta de análise semânticodiscursiva e a Gramática do Design Visual, ambas de base sistêmico-funcional. Assim, com base nas teorias consideradas, esta tese leva em conta que o livro didático de inglês é um gênero discursivo presente na cultura educacional brasileira e que carrega em si outros gêneros; e também que ele é um objeto de representação dada sua relevância na sociedade em termos políticos, econômicos, culturais e pedagógicos. Este estudo apresenta, então, análise do discurso de produtores de livros didáticos de inglês, considerando gêneros discursivos produzidos por autores e ou editores sobre cinco coleções didáticas distintas (anúncios de catálogos, quartas capas, e apresentações em manuais do professor) bem como análise do discurso de usuários considerando entrevistas com 12 professores usuários de volumes dessas coleções, e 116 questionários com alunos destes docentes sobre o livro utilizado. Estes livros são usados em cinco estabelecimentos de ensino diferentes localizados em Belo Horizonte e no Rio de Janeiro. A pesquisa é de cunho qualitativo, caracteriza-se pela multiplicidade, e seu caráter construtivista está presente na explicitação das representações através da análise do uso cotidiano da linguagem, nomeando-as e sistematizando-as a partir de elementos verbais e não verbais presentes e recorrentes no corpus. Esta em si é uma das contribuições deste estudo. As análises indicam que produtores e usuários, em geral, representam o livro didático de inglês como fonte, agente, 
curso e atração, sendo pouco recorrentes as representações do livro didático como facilitador e guia no discurso dos produtores. Já a análise do discurso dos usuários evidencia que os docentes ainda representam o livro de inglês como organizador, suporte, mercadoria, possibilidade, e curso. Diferentemente dos produtores, os usuários (professores e alunos) veem o livro didático como facilitador e como guia de maneira mais recorrente. $\mathrm{O}$ estudo mostra que os mesmos recursos de significação, ou semelhantes, contribuem para a construção das representações na e pela linguagem, e que as representações também estão relacionadas entre si. Os recursos de significação que contribuem para a construção das representações são de cunho ideacional, interpessoal e textual, não estando estas, então, limitadas ao aspecto ideacional da linguagem. Além de evidenciar as representações, este estudo ainda sugere que essas representações regulam as práticas sociais de produtores e usuários de livros didáticos. Outras contribuições desta tese podem ser a aplicação dos conhecimentos aqui produzidos em cursos de formação de professores, a promoção de conscientização sobre o discurso a respeito do livro didático em momentos de seleção e avaliação do material, e constituindo-se como um ponto de partida para investigações futuras.

\section{Palavras-chave}

Livro didático de inglês; discurso; representações; Linguística Aplicada; Linguística Sistêmico Funcional; produtores; usuários 


\section{Abstract}

Silva, Renato Caixeta da; Hemais, Barbara Jane Wilcox (Advisor). Representations of English Language Coursebooks: analysis of the discourse of producers and users from a systemic-functional approach. Rio de Janeiro, 2012. 332p. Doctoral Thesis - Departamento de Letras, Pontifícia Universidade Católica do Rio de Janeiro.

This thesis investigates the representations of English language coursebooks that are socially constructed by their producers (authors and editors) and their users (teachers and students). Systemic-functional linguistics and knowledge about representations from Cultural Studies and Social Psychology constitute the theoretical basis of the study, from a view of social construction of reality. More specifically, a semantic-discursive analysis and the grammar of visual design, both based on the systemic-functional theory of language, serve as guides for the discourse analysis. Using these theories, the thesis takes the English coursebook as a genre that is present in Brazilian educational culture and that carries other genres in itself; it is also an object of representation due to its political, economic, cultural and pedagogical relevance in society. Thus, this study presents an analysis of English coursebook producers' discourse in five separate series, considering three genres written by authors and editors: catalogue advertisements, back cover blurbs and teacher's manual introductions. The study also analyzes the users' discourse through 12 interviews with teachers who adopt volumes from these series, and 116 questionnaires answered by their students. The coursebooks are adopted by five different teaching institutions located in Belo Horizonte and Rio de Janeiro. This research is qualitative, characterized by multiplicity, and it uses a constructivist approach in the sense that the explicitness of the representations is expressed in the everyday use of language, which the analytical procedure identifies, categorizes, and systematizes from the recurrent verbal and non verbal elements in the corpus. This is one of the contributions of the research. The analysis indicates that producers and users, in general, represent the English coursebook as a source, an agent, the course, and an attraction. In the coursebook producers' discourse, guide and facilitator are less recurrent representations. On 
the other hand, the analysis of the users' discourse shows that teachers still represent the coursebook as an organizer, a base, a piece of merchandise, and a possibility. Differently from the producers, users (teachers and students), more recurrently, see the coursebook as a facilitator and a guide. The study shows that the same meaning resources, or similar ones, contribute towards the construction of the representations in and through language, and that the representations are themselves inter-related. These meaning resources are ideational, interpersonal and textual ones, and this suggests representations are not limited to ideational aspects of language only. Furthermore, this research also suggests these representations regulate coursebook producers' and users' social practices. The pedagogical contributions of the study may be the application of the knowledge produced here for teacher education; a greater awareness of the discourse on the English coursebook that might help in materials evaluation and coursebook selection processes; and a starting point for future investigations on the topic.

\section{Keywords}

English coursebook; discourse; representations; Applied Linguistics; Systemic Functional Linguistics; producers; users 


\section{Sumário}

1-Introdução 17

1.1. A proposta de estudo 17

1.2.Este estudo como um trabalho de Linguística Aplicada 21

1.3.Justificativa 23

1.4. Estrutura da tese 28

2- A Linguística Sistêmico-Funcional 30

2.1. A concepção sociossemiótica da linguagem 31

2.2. A definição de texto 33

2.3. As metafunções

2.4. O contexto de situação ou de registro 36

2.5. Contexto de cultura 38

2.6. A definição de gêneros discursivos 41

2.7. A Gramática proposta na Linguística Sistêmico-Funcional 43

2.7.1. Sistemas de significação no âmbito da oração 45

a. Ideacional - construção das experiências 45

b. Interpessoal - troca 51

c. Textual - a estrutura Tema e Rema 54

2.8. Além da oração: propostas de análises discursivas 55

2.8.1. A proposta de análise discursiva de Martin \& Rose: "o significado além da sentença".

a. Avaliatividade $\quad 58$

b. Ideação $\quad 62$

c. Periodicidade 67

2.8.2. A Gramática do Design Visual (Kress \& van Leeuven, 1996) 69

$\begin{array}{ll}\text { a. A construção de significados ideacionais } & 71\end{array}$

b. A construção de significados interpessoais 77

c. A construção de significados textuais: a composição 80

2.9. Considerações finais do capítulo 82

3- Representações $\quad 84$

3.1. O conceito de representações $\quad 84$

3.2. Representações e Discurso 90

3.3. Pesquisando representações 94

3.4. Considerações finais do capítulo 97

4- O livro didático de inglês como língua estrangeira 99

4.1. Definições de livro didático 99

4.2. O livro didático enquanto gênero discursivo 101

4.3. Estudos sobre o livro didático de inglês como língua estrangeira 104

4.4. A produção de livros didáticos de inglês 108

4.5. Importância do livro didático de inglês como língua estrangeira 109

4.5.1. Importância política 109

4.5.2. Importância econômica 112

4.5.3. Importância cultural 115

4.5.4. Importância pedagógica 118

4.6. O livro didático de inglês como objeto de representações 120

4.7. Considerações finais do capítulo 122

$\begin{array}{ll}\text { 5- Metodologia } & \mathbf{1 2 4}\end{array}$

5.1. Caracterização metodológica da pesquisa $\quad 124$

5.1.1. Enquadramento da pesquisa num paradigma construtivista 124

5.1.2. A investigação enquanto pesquisa qualitativa 126

5.2. A pesquisa 128

5.2.1. Descrição do corpus 128

5.2.2. Descrição dos contextos 134

5.2.3. Procedimentos e instrumentos de coleta de dados 137

5.2.4. Procedimentos de análise 140

5.3. Considerações finais do capítulo 143 
6.1. Anúncios em catálogos de editoras

6.1.1. Os gêneros catálogo de editoras e anúncios de coleções didáticas 146

6.1.2. As representações construídas nos anúncios de coleções didáticas 150

a. O livro didático como fonte 151

b. O livro didático como agente 158

c. O livro didático como curso 161

d. O livro didático como atração 162

6.2. Quartas capas de livros didáticos de inglês 164

6.2.1. O gênero quarta capa 164

6.2.2. As representações construídas nas quartas capas 166

a. Fonte 166

$\begin{array}{ll}\text { b. Agente } & 178\end{array}$

c. Curso 181

d. Atração 184

6.3. Apresentações de livros didáticos de inglês em manuais de professores 187

6.3.1. O manual do professor e a apresentação como gêneros discursivos 187

6.3.2. As representações construídas nas apresentações de manuais do professor

$\begin{array}{lll}\text { a. } & \text { O livro como fonte } & 190 \\ \text { b. } & \text { O livro como agente } & 203 \\ \text { c. } & \text { O livro como facilitador } & 208 \\ \text { d. } & \text { O livro como curso } & 211 \\ \text { e. } & \text { O livro como atração } & 216 \\ \text { f. } & \text { O livro como guia } & 220\end{array}$

6.4. Considerações finais do capítulo 221

7- 0 discurso dos usuários 225

7.1. O que dizem os professores. 225

7.1.1. A entrevista como gênero discursivo 225

7.1.2. Caracterização dos docentes 228

7.1.3. As representações do livro didático no discurso de professores 230

a. O livro didático como fonte 230

b. O livro didático como agente 241

c. O livro didático como guia 246

d. O livro didático como facilitador 251

e. O livro didático como atração 255

f. O livro didático como suporte 259

g. Outras representações 261

7.2. O que escrevem os alunos $\quad 267$

7.2.1. Questionário como gênero discursivo 267

7.2.2. As representações do livro didático de inglês nas respostas dos alunos 269

a. O livro didático como fonte 270

b. O livro didático como agente 278

c. O livro didático como facilitador 282

d. O livro didático como guia 285

7.3. Considerações finais do capítulo 290

8- Reflexões 292

8.1. Síntese das representações sobre o livro didático de inglês e o conceito
de topologia

8.2. Complementaridade entre teoria sistêmico-funcional da linguagem e estudos de representações $\quad 297$

8.3. Representações e a regulação de práticas com o livro didático 299

8.4. Influência do discurso de produtores no discurso de usuários: apenas
uma questão

8.5. Considerações finais do capítulo. $\quad 305$

9- Conclusão e considerações finais $\quad 306$

Referências bibliográficas $\quad 313$

Anexos $\quad 325$ 


\section{Lista de figuras}

Figura 1: Design da Pesquisa de Doutorado

Figura 2: Relação dos significados e estratos da língua (Fontes: Halliday, 1994; Eggins, 1994; Halliday \& Mathiessen, 2004)

Figura 3: Relação dos contextos de cultura e de situação com a língua. Fonte: Halliday (1994), Eggins (1994), Eggins (2004).

Figura 4: Exemplo de estrutura narrativa. Fonte: Panfleto da coleção Framework (s/d) Ed. Richmond.

Figura 5: Exemplo de processo classificatório. Fonte: Oxford English Language Teaching Brazil Catalogue, 2008-2009, p. 23.

Figura 6: Exemplo de processo analítico. Fonte: OXEDEN, C., LATHANKOENIG, C., \& HAMILTON, G. English File Upper-Intermediate Teacher's Book. Oxford: OUP, 2001/2002, p.4.

Figura 7: Exemplo de processo simbólico. Fonte: Quarta Capa do Livro New Ace 1, Teacher's Edition, Ed. Longman.

Figura 8: Roteiro de entrevista com professores sobre representações acerca do livro didático de inglês.

Figura 9: Questionário aplicado aos alunos participantes

Figura 10: Parte da apresentação ao professor do livro New Ace 1

Figura 11: Partes da apresentação ao professor do livro New American Inside Out Elementary

Figura 12: Esquema ilustrando a subseção Student's Book, English File UpperIntermediate, Teacher's Book

Figura 13: Moldura sobre website - da apresentação de New American Inside Out Elementary

Figura 14: Representações do livro didático de inglês nos discursos de produtores e usuários. 


\section{Lista de quadros}

Quadro 1: Estratos da língua (Fonte: Eggins, 2004, p.19 adaptado) 32

Quadro 2: Processos e participantes - significados ideacionais. Fonte Halliday 50 (1994); Halliday \& Mathiessen (2004), Eggins (2004)

Quadro 3: Circunstâncias - significados ideacionais. Fonte: Halliday (1994); 51 Halliday \& Mathiessen (2004)

Quadro 4: Papéis discursivos dos interlocutores- significado interpessoal. Fonte: 52 Halliday (1994); Halliday \& Mathiessen (2004)

Quadro 5: Processos e participantes - significação ideacional com exemplo. 64 (Fonte: Martin \& Rose, 2003)

Quadro 6: Relações taxonômicas (baseado em Martin \& Rose, 2003 e Martin \& 65 Rose, 2007)

Quadro 7: Livros didáticos de inglês utilizados e respectivos contextos de uso 129 considerados.

Quadro 8: Panorama do conjunto de entrevistas 132

Quadro 9: Panorama de dados coletados com alunos através de questionários. 133

Quadro 10: Ocorrências de sentenças com processos materiais indicando 167 provimento em quartas capas.

Quadro 11: Ocorrências de sentenças com processos relacionais atributivos 168 possessivos em quartas capas

Quadro 12: Exemplos de Temas e Novos em textos de quartas capas de livros 176 didáticos de inglês

Quadro13: Processos do âmbito do Fazer em quartas capas de livros didáticos de inglês

Quadro14: Ocorrência de atividades (Fazer e Ser) em textos de apresentação de livros didáticos em manuais do professor.

Quadro 15: Apreciações relacionadas à composição em apresentações de manuais do professor

Quadro 16: Atividades do Âmbito do Fazer em apresentações de manuais do professor

Quadro17: Informações sobre os docentes entrevistados.

Quadro 18: Quantidade aproximada de processos do âmbito do Ser indicando posse e existências nas entrevistas com professores

Quadro 19: Quantidade e exemplos de sentenças com processos materiais indicando provimento em entrevistas com professores

Quadro 20: Sentenças com processos do âmbito do Fazer nas entrevistas com professores - livro didático como agente

Quadro 21: Quantidade de alunos respondentes nos diferentes contextos

Quadro 22: Respostas dos questionários com referência ao livro didático, componente da obra ou elementos do volume utilizado

Quadro 23: Respostas dos questionários com processos do âmbito do Ser

Quadro 24: Identificação e classificação do livro didático de inglês como fonte pelos alunos

Quadro 25: Atitudes positivas relacionadas à composição da obra didática quantidade e exemplos

Quadro 26: Resposta de alunos em que o livro didático é participante agente de processos do Fazer ou do Dizer / Sentir - quantidade e exemplos

Quadro 27: Livro didático como agente de processos que denotam facilitação

Quadro 28: O Discurso de Produtores de Livros Didáticos de Inglês

Quadro 29: O Discurso de Usuários de Livros Didáticos de Inglês 


\section{Lista de esquemas}

Esquema 1: Sistema de Avaliatividade. Fonte: Martin \& Rose (2003, p.54)

Esquema 2: Tipos de estrutura visual. (Fonte: Kress \& van Leeuwen, 1996, p.56)

Esquema 3: Estruturas narrativas visuais (adaptado de Kress \& van Leeuwen (1996, p.73)

Esquema 4: Processos de classificação - design de construtos sociais (adaptado de Kress \& van Leeuwen, 1996, p.88)

Esquema 5: Processos simbólicos: design de construtos sociais (adaptado de Kress \& van Leeuwen, 1996, p.108)

Esquema 6: Significados interacionais em imagens (adaptado de Kress \& van Leeuwen, 1996, p. 154)

Esquema 7: Significados textuais em imagens e textos multimodais (adaptado de Kress \& van Leeuwen, 1996, p. 223)

Esquema 8: Relação todo-partes: componentes e elementos da coleção Straightforward - anúncio de catálogo

Esquema 9: Relação todo-partes: componentes e elementos da coleção New American Inside Out - anúncio de catálogo

Esquema 10: Relação todo-partes: componentes e elementos da coleção English File - anúncio de catálogo.

Esquema 11: Relação Taxonômica: componentes e elementos da coleção New American Inside Out - quarta capa

Esquema 12: Relação Taxonômica: componentes e elementos de New Ace 1quarta capa

Esquema 13: Relação todo - parte: os componentes do livro Straightforward Elementary na apresentação do manual do professor

Esquema 14: Relação todo-parte: os componentes do livro English File UpperIntermediate na apresentação do manual do professor

Esquema 15: Relação todo-parte: os componentes do livro New Ace 1 na apresentação do manual do professor

Esquema 16: Relação todo-parte: os componentes do livro New American Inside Out Elementary na apresentação do manual do professor

Esquema 17: Relação todo-parte: os componentes do livro Framework Intermediate na apresentação do manual do professor

Esquema 18: Organização do texto de apresentação no manual do professor de Framework Intermediate 
"É que a vida é para todos um fato cotidiano. Ela o é pela dinâmica mesma de suas contradições, pelo equilíbrio mesmo de seus pólos contrários. O homem não poderia viver sob o sentimento permanente dessas contradições e desses contrários, que procura constantemente esquecer para poder mover a máquina do mundo, da qual é o único criador e obreiro, e para não perder a sua razão de ser dentro de uma natureza em que constitui ao mesmo tempo a nota mais bela e mais desarmônica. Ou melhor: para não perder a razão tout court." 